
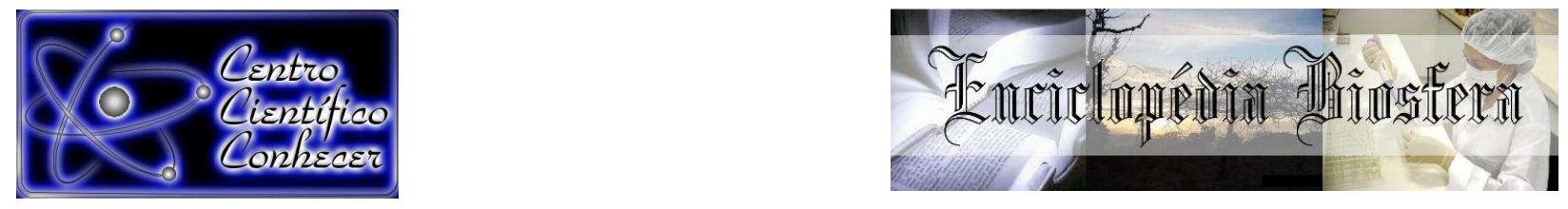

\title{
AVALIAÇÃO DA CONCENTRAÇÃO DO MERCADO MUNDIAL DE PELLETS DE MADEIRA E AS OPORTUNIDADES PARA O BRASIL
}

Bruno Leão Said Schettini ${ }^{1}$, Márcio Lopes da Silva², Laércio Antônio Gonçalves Jacovine $^{3}$, Eliana Boaventura Bernardes Moura Alves ${ }^{4}$, Paulo Henrique Villanova ${ }^{5}$

'Universidade Federal de Viçosa, estudante de mestrado em Ciência Florestal, Viçosa, Minas Gerais, Brasil. E-mail: blsschettini@gmail.com.

2Universidade Federal de Viçosa, professor do departamento de Engenharia Florestal, Viçosa, Minas Gerais, Brasil.

3Universidade Federal de Viçosa, professor do departamento de Engenharia Florestal, Viçosa, Minas Gerais, Brasil.

${ }^{4}$ Universidade Federal de Viçosa, estudante de doutorado em Ciência Florestal, Viçosa, Minas Gerais, Brasil.

${ }^{5}$ Universidade Federal de Viçosa, estudante de mestrado em Ciência Florestal, Viçosa, Minas Gerais, Brasil.

Recebido em: 08/04/2016 - Aprovado em: 30/05/2016 - Publicado em: 20/06/2016 DOI: 10.18677/Enciclopedia_Biosfera_2016_009

\begin{abstract}
RESUMO
Objetivou-se com este trabalho verificar a concentração de mercado internacional de pellets bem como as oportunidades para crescimento do Brasil nesse setor. Para tal, foi avaliada a desigualdade do mercado pelo Coeficiente de Gini e a concentração pela razão dos quatro e oito principais exportadores. Foram utilizados dados de exportação de 62 nações fornecidos pela Organização das Nações Unidas para Alimentação e Agricultura (FAO), no período de 2012 a 2014. De acordo com os resultados obtidos, o índice de desigualdade do mercado é classificado como forte a muito forte e a sua concentração é moderada. Os Estados Unidos (EUA) foi o principal exportador de pellets no período avaliado, sendo que, em 2014, detinha $26,8 \%$ do total das exportações. Nota-se também a importância de outros países, que nos três anos, se mantiveram como principais exportadores do produto, como Canadá e Letônia. O Brasil, apesar de não ser um dos principais exportadores dos pellets de madeira, aumentou sua participação no mercado consideravelmente, uma vez que foram exportadas 6 toneladas do produto em 2012 e em 2014 esse valor foi de 6.660 toneladas, o que evidencia que o país possui condições de ter maior inserção nesse mercado.
\end{abstract}

PALAVRAS-CHAVE: Competitividade de mercado. Organização das Nações Unidas para Alimentação e Agricultura. Tecnologia da madeira 


\title{
EVALUATION OF THE WORLD MARKET CONCENTRATION FOR WOOD PELLETS AND THE OPPORTUNITIES FOR BRAZIL
}

\begin{abstract}
This study aimed to determine the concentration of international pellets market and the opportunities for Brazil's growth in this sector. For this, we evaluate the inequality of the market by the Gini coefficient and the concentration by ratio of the four and eight major exporters. We used export data from 62 nations provided by Food and Agriculture Organization (FAO) in the period from 2012 to 2014. According to the results, the market inequality index is classified as strong to very strong and its concentration is moderate. The United States (US) was the main exporter of pellets during the study period, and in 2014 held $26.8 \%$ of total exports. It is also noted the importance of other countries, which in three years remained as leading exporters of the product, such as Canada and Latvia. The Brazil, despite not being a major exporter of wood pellets, increased its share considerably market, as were exported 6 tons of product in 2012 and in 2014 this figure was 6,660 tons, which shows that the country has able to have greater presence in this market.
\end{abstract}

KEYWORDS: Food and agriculture organization of the united nations. Market competitiveness. Wood technology.

\section{INTRODUÇÃO}

Devido à crescente demanda da população mundial por energia e do aumento da expectativa de vida em países emergentes, a procura por novas fontes energéticas está cada vez mais em evidência (CONSTANTINI et al., 2016). Os pellets surgiram como uma opção viável e tecnológica para contornar essa situação (PROTÁSIO et al., 2015), pois são um combustível de matriz limpa, renovável e com elevado teor energético (SELKIMAKI et al., 2010). Pellets são biocombustíveis sólidos granulados produzidos a partir da densificação de partículas de biomassa, com ou sem aditivos, formato cilíndrico, diâmetro pré-definido de 6 a $25 \mathrm{~mm}$ e comprimento variável (DIN, 2011).

A demanda pelo produto tem aumentado ao longo dos anos, principalmente no mercado europeu, devido à legislação que apoia a utilização de combustíveis de fontes renováveis (TRØMBORG et al., 2013). Em 2011, o consumo mundial de pellets foi de 14,4 milhões de toneladas, desse total, $80 \%$ foram consumidos somente na União Europeia (MOBINI et al., 2013). No ano de 2013, a produção de pellets de madeira na União Europeia foi superior a 12 milhões de toneladas, enquanto o consumo foi de 18,7 milhões de toneladas (KRISTÖFEL et al., 2015). Observa-se, na União Europeia, que os pellets são cada vez mais utilizados para geração de energia térmica e elétrica, em aplicações industriais e comerciais, em média e grande escala (GOETZL, 2015).

Enquanto alguns países, como Alemanha e Áustria, consomem grande parte da sua produção de pellets, outros dependem das importações para suprir a demanda, como é o caso do Reino Unido, Itália, Dinamarca, Bélgica e Suécia (GOETZL, 2015). De acordo com o mesmo autor, as indústrias norte-americanas e canadenses são as principais responsáveis por cobrir a necessidade de importação de pellets nesses países, sendo que em 2014, exportaram 5,64 milhões de toneladas de pellets para a União Europeia. 
Para determinar essa estrutura de mercado, são utilizadas as medidas de concentração e classificação. Elas são importantes porque, acredita-se que, algumas empresas utilizam tais parâmetros para reorganizar as atividades de produção (HENNESSY et al., 2007). Além disso, a estrutura do mercado pode afetar tanto a sua própria eficiência quanto alterar incentivos à inovação (AGHION et al., 2005). Tem-se como principais medidas de concentração, o Coeficiente de Gini e as razões de concentração (HENNESSY et al., 2007).

Já foram publicados estudos sobre concentração de mercado florestal, dentre eles o de NOCE et al. (2005), sobre o mercado internacional de madeira serrada; NOCE et al. (2007), para o mercado internacional de compensado; NOCE et al. (2008), para o mercado internacional de aglomerado; COELHO JUNIOR et al. (2013), para as exportações de produtos florestais. Porém, não há estudos caracterizando a concentração do mercado internacional de pellets.

O estudo da estrutura do mercado internacional dos pellets faz-se necessário para compreender a dinâmica da comercialização desse produto. Dessa forma, o objetivo do presente trabalho foi avaliar a concentração do mercado internacional de pellets de madeira no período de 2012 a 2014, a partir das medidas de concentração de mercado e de desigualdade, bem como as oportunidades para o Brasil possuir maior representatividade no mercado internacional de pellets de madeira.

\section{MATERIAL E MÉTODOS}

Os dados foram extraídos do banco de dados da Organização Das Nações Unidas Para Alimentação e Agricultura (FAO, 2015) e referem-se aos valores das exportações de pellets de madeira para 62 países, nos anos de 2012, 2013 e 2014. Foram calculadas medidas de desigualdade e concentração de mercado para avaliar as exportações de pellets de madeira.

\section{MEDIDAS DE DESIGUALDADE COEFICIENTE DE GINI} (2005).

Coeficiente de Gini foi calculado pela equação proposta por NOCE et al.

$$
G=1-\sum_{i=1}^{n}(C i j+C i)
$$

Em que:

$\mathrm{G}=$ índice de Gini;

$\mathrm{n}$ = número de países;

$\mathrm{Cij}=$ participação acumulativa no consumo em ordem crescente; e

$\mathrm{Ci}=$ participação da fábrica $\mathrm{i}$.

A classificação do nível de concentração de um mercado segundo os valores do Índice de Gini foi feita de acordo com os critérios apresentados na Tabela 1. 
TABELA 1: Classificação da desigualdade pelo Coeficiente de Gini. Fonte: NOCE et al. (2005).

\begin{tabular}{cc}
\hline Valor do Índice de Gini & Desigualdade do Mercado \\
\hline $0,101-0,250$ & Nula a fraca \\
$0,251-0,500$ & Fraca a média \\
$0,501-0,700$ & Média a forte \\
$0,701-0,900$ & Forte a muito forte \\
$0,901-1,000$ & Muito forte a absoluta \\
\hline
\end{tabular}

\section{CONCENTRAÇÃO DE MERCADO}

A concentração de mercado corresponde a porcentagem de vendas dos quatro e/ou oito principais países exportadores, neste caso, de pellets de madeira. Quando consideradas as quatro principais nações exportadoras, os níveis de mercado podem variar de claramente atomístico para altamente concentrado. Já quando são considerados os oito países exportadores, os níveis variam de ausência de concentração até altamente concentrado (Tabela 2).

TABELA 2: Classificação dos mercados segundo a razão de concentração. Fonte: HEIMANN et al. (2015).

\begin{tabular}{ccc}
\hline Níveis de Mercado & CR4 & CR8 \\
\hline Altamente concentrado & $\mathrm{i}>75 \%$ & $\mathrm{i}>90 \%$ \\
Alta concentração & $65 \%<i<75 \%$ & $85 \%<\mathrm{i}<90 \%$ \\
Concentração moderada & $50 \%<i<65 \%$ & $70 \%<i<85 \%$ \\
Baixa concentração & $35 \%<i<50 \%$ & $45 \%<i<70 \%$ \\
Ausência de concentração & $\mathrm{i}<35 \%$ & $\mathrm{i}<45 \%$ \\
Claramente atomístico & $\mathrm{i}=2 \%$ & - \\
\hline
\end{tabular}

CR4: Concentração de mercado dos 4 principais exportadores. CR8: Concentração de mercado dos 8 principais exportadores.

\section{RESULTADOS E DISCUSSÕES}

\section{PRINCIPAIS PAÍSES EXPORTADORES DE PELLETS DE MADEIRA}

No ano de 2012 foram exportadas 9,7 milhões de toneladas de pellets, já no ano de 2014 esse valor foi superior a 14,9 milhões, o que representou um aumento de aproximadamente $65 \%$ nas exportações do produto (FAO, 2015) (Tabela 3). Os Estados Unidos (EUA) foi o principal exportador de pellets de madeira no período avaliado, sendo que em 2014 representava $26,8 \%$ do total exportado. Nota-se também a importância de outros países, que nos três anos se mantiveram como principais exportadores do produto, Canadá e Letônia (Tabela 4). O Brasil, no período avaliado, alavancou suas exportações de 6 toneladas em 2012 para 6.660 em 2014. Esse crescimento no curto período e os investimentos feitos no setor podem possibilitar maior inserção do país no mercado internacional nos próximos anos. 
TABELA 3: Dez principais exportadores de pellets nos anos de 2012, 2013 e 2014 em números brutos.

\begin{tabular}{|c|c|c|c|c|c|}
\hline \multirow{2}{*}{$\begin{array}{c}\text { Ano } \\
\text { Países }\end{array}$} & \multirow{2}{*}{$\begin{array}{c}2012 \\
\begin{array}{c}\text { Exportações } \\
\text { (ton) }\end{array}\end{array}$} & \multicolumn{3}{|c|}{2013} & \multirow{2}{*}{$\begin{array}{c}2014 \\
\text { Exportações }\end{array}$} \\
\hline & & Países & Exportações & Países & \\
\hline EUA & 1.898 .125 & EUA & 2.882 .517 & EUA & 4.005 .057 \\
\hline Canadá & 1.369 .000 & Canada & 1.640 .231 & Canadá & 1.637 .393 \\
\hline Letônia & 902.031 & Letônia & 1.055 .869 & Letônia & 1.277 .087 \\
\hline Alemanha & 848.777 & Portugal & 776.743 & Rússia & 879.028 \\
\hline Rússia & 728.540 & Rússia & 743.626 & Portugal & 749.602 \\
\hline Portugal & 581.081 & Alemanha & 720.204 & Vietnam & 746.000 \\
\hline Áustria & 476.279 & Estônia & 612.742 & Estônia & 640.838 \\
\hline Estônia & 430.425 & Áustria & 482.798 & Alemanha & 627.088 \\
\hline Romênia & 276.702 & Romênia & 456.608 & Áustria & 480.754 \\
\hline Lituânia & 267.792 & Bélgica & 394.221 & Romênia & 412.915 \\
\hline Brasil & 6 & Brasil & 194 & Brasil & 6660 \\
\hline Total & 7.778 .752 & & 9.765 .559 & & 11.455 .762 \\
\hline
\end{tabular}

TABELA 4: Dez principais exportadores de pellets nos anos de 2012, 2013 e 2014 em percentual.

\begin{tabular}{cccccc}
\hline $\begin{array}{c}\text { Ano } \\
\text { Países }\end{array}$ & $\begin{array}{c}\mathbf{2 0 1 2} \\
\text { Participação (\%) }\end{array}$ & Países & $\begin{array}{c}\mathbf{2 0 1 3} \\
\text { Participação (\%) }\end{array}$ & Países & $\begin{array}{c}\mathbf{2 0 1 4} \\
\text { Participação (\%) }\end{array}$ \\
\hline EUA & 19,47 & EUA & 22,92 & EUA & 26,80 \\
Canadá & 14,04 & Canada & 13,05 & Canadá & 10,96 \\
Letônia & 9,25 & Letônia & 8,40 & Letônia & 8,55 \\
Alemanha & 8,70 & Portugal & 6,18 & Rússia & 5,88 \\
Rússia & 7,47 & Rússia & 5,91 & Portugal & 5,02 \\
Portugal & 5,96 & Alemanha & 5,73 & Vietnam & 4,99 \\
Áustria & 4,88 & Estônia & 4,87 & Estônia & 4,29 \\
Estônia & 4,41 & Áustria & 3,84 & Alemanha & 4,20 \\
Romênia & 2,84 & Romênia & 3,63 & Áustria & 3,22 \\
Lituânia & 2,75 & Bélgica & 3,14 & Romênia & 2,76 \\
$\ldots$ & $\ldots$ & $\ldots$ & $\ldots$ & $\ldots$ & $\ldots$ \\
Brasil & 0,00006 & Brasil & 0,00154 & Brasil & 0,04457 \\
\hline Total & $\mathbf{7 9 , 7 7}$ & & $\mathbf{7 7 , 6 6}$ & & $\mathbf{7 6 , 6 7}$ \\
\hline \multicolumn{7}{r}{} & & & & \\
\hline
\end{tabular}

A capacidade de produção norte-americana de pellets de madeira entre os anos de 2003 e 2010 aumentou de 1,1 para 4,9 milhões de toneladas (NUNES et.al, 2015), porém EUA e Canadá possuíam perfis diferentes de destinação do produto, enquanto nos EUA quase $80 \%$ do que era produzido era consumido internamente, no Canadá a maioria da produção era exportada (SPELTER et al., 2009). A partir de 2009, foram construídas usinas para produção de pellets destinados à exportação nos EUA (SIKKEMA et al., 2011). Os aumentos da capacidade de produção, ENCICLOPÉDIA BIOSFERA, Centro Científico Conhecer - Goiânia, v.13 n.23; p. 1072016 
atrelados ao aumento da demanda do produto na União Europeia, fizeram com que o país se tornasse o principal exportador do produto.

Nos três anos avaliados, a Letônia se manteve como a terceira maior exportadora de pellets, cujos principais mercados consumidores foram a Finlândia, onde 33\% da importação de pellets de madeira foi proveniente da Letônia, Dinamarca e Suécia (SIKKEMA et al., 2011; TRØMBORG et al., 2013).

Apesar da representatividade percentual da Alemanha e Áustria nas exportações de pellets terem diminuído ao longo dos anos, a produção não diminuiu. Nesses países, os pellets de madeira são predominantemente consumidos internamente, em aplicações residenciais, tais como caldeiras e fornos (PESKABLANCHARD et al., 2007). A Alemanha, devido às leis fiscais favoráveis, é um dos mercados mais promissores da Europa, com a produção de pellets sendo estimada em 1,2 milhões de toneladas para o ano de 2010 (KARKANIA et al., 2012). Na Áustria, no ano de 2014, a produção de pellets continuou em crescimento atingindo cerca de 950 mil toneladas do produto, $85 \%$ desse total é consumido no próprio país (KRISTÖFEL et al., 2015), fato que também justifica a menor representatividade do país nas exportações mundiais no período estudado.

Entre os anos de 2012 e 2014, a participação de Portugal nas exportações oscilou. Tal fato ocorreu devido ao mercado português encontrar-se em fase inicial de desenvolvimento, além de ser desestruturado (SIKKEMA et al., 2011). A Rússia também tem importante papel no mercado de pellets, uma vez que nos anos de 2012 e 2013 foi a quinta maior exportadora de pellets de madeira, enquanto em 2014 foi a quarta, devido a construção de mais de 200 plantas de pellets no país nos últimos anos (PROSKURINA et al., 2015). Segundo os autores, apenas $15 \%$ dos pellets produzidos na Rússia são consumidos no próprio país.

É possível notar que em alguns países como Canadá, Alemanha e Rússia, apesar das exportações terem aumentando em números brutos, a representatividade em termos percentuais diminuiu ao longo dos anos, tal fato ocorreu devido ao aumento nas exportações dos EUA.

Diferentemente do contexto de mercado bem consolidado relatado, os pellets para uso energético são pouco conhecidos e utilizados no Brasil, sendo que as poucas indústrias instaladas atualmente têm a produção voltada para o mercado externo.

Devido ao crescente consumo de pellets pelo mercado europeu, há perspectivas para o desenvolvimento da produção de pellets no Brasil, que reúne características interessantes como disponibilidade de matéria-prima, resíduos agrícolas e florestais, além de terras e condições edafoclimáticas satisfatórias para plantios florestais ou agrícolas exclusivamente para produção de pellets.

No período avaliado, as exportações de pellets do Brasil aumentaram consideravelmente, no ano de 2012 foram exportadas 6 toneladas do produto e em 2014 esse valor foi de 6.660 toneladas (FAO, 2015), esse aumento das exportações ocorreu principalmente pelo funcionamento de novas fábricas para produção de pellets de madeira no sul do país (SPANHOL et al., 2015).

O Brasil possui condições de aumentar sua participação no mercado internacional de pellets, assim como aconteceu no mercado de celulose, onde o país em 20 anos se tornou o sexto maior produtor de celulose no mundo, superando países como Japão, Rússia e Indonésia (COSTA et al., 2009). 


\section{MEDIDAS DE DESIGUALDADE}

Com base no Coeficiente de Gini, foi possível classificar, no período avaliado, a desigualdade do mercado de forte a muito forte, com valores de 0,8538 em 2012; 0,8599 em 2013; e 0,8640 em 2014. A principal razão para isso é a concentração das exportações do produto pelos EUA que possuem a maior participação nas exportações de pellets. No ano de 2014 , detinham $26,8 \%$ do total das exportações, valor superior em $100 \%$ em relação ao segundo maior exportador, o Canadá.

Alguns países como Áustria, Alemanha, Suécia, Dinamarca e Holanda são os principais consumidores de pellets de madeira na União Européia (SIKKEMA et al., 2011) e dependem das importações provenientes de Canadá e EUA para suprir a demanda do produto (LAMERS et al., 2012). Essa diversidade de consumidores que concentram as importações em dois países contribui também para desigualdade superior no mercado.

Quando comparado com o mercado de painéis aglomerados, é possível notar que o de pellets de madeira possui desigualdade é inferior. NOCE et al. (2008), ao avaliarem a competitividade do mercado internacional de painéis aglomerados, também pelo Índice de Gini, nos períodos de 1998 a 2000 e 2000 a 2002, classificaram o mercado com desigualdade muito forte à absoluta. Segundo os autores, essa desigualdade no mercado de painéis aglomerados ocorreu devido à concentração das exportações em poucos países, fato esse que também é observado no mercado de pellets de madeira.

NOCE et al. (2005), ao avaliarem a concentração do mercado de madeira serrada, no período de 1997 a 1999, classificaram-no pelo Índice de Gini com desigualdade muito forte a absoluta, devido à concentração das exportações do produto em dois países, Canadá e Suécia, que juntos contribuíam com aproximadamente $60 \%$ do total exportado. O mercado de compensados de madeira, no período de 1998 a 2002, foi classificado também com desigualdade forte e absoluta (NOCE et al., 2007), uma vez que as quatro principais nações exportadoras do produto concentravam mais de $50 \%$ do total exportado.

COELHO JÚNIOR et al. (2013) ao avaliarem a concentração de mercado de produtos florestais, pelo Coeficiente de Gini, no período de 1961 a 2008, concluíram que a desigualdade do mercado é forte e absoluta. A justificativa para tal fato é que apesar do aumento de exportadores de produtos florestais ao longo do período de análise, um número reduzido de competidores concentra frações cada vez maiores das exportações internacionais desses produtos.

Apesar de, entre os anos de 2012 e 2014, a desigualdade do mercado de pellets de madeira ter aumentado, ele ainda se manteve classificado como forte a muito forte, em virtude do elevado número de países que exportam o produto. Diferentemente do mercado de produtos florestais, compensados, painéis aglomerados e madeira serrada, que foram classificados com desigualdade forte e absoluta, devido aos poucos países dominarem as exportações desses produtos.

\section{CONCENTRAÇÃO DO MERCADO}

Os resultados dos índices de Razão de Concentração CR4 indicaram uma concentração moderada do mercado. Tal fato ocorre uma vez que EUA, Canadá, Rússia e Portugal quando analisados de forma conjunta, representam aproximadamente $50 \%$ das exportações mundiais (Tabela 5). 
TABELA 5: Concentração de mercado para os 4 e 8 maiores exportadores de pellets nos anos de 2012, 2013 e 2014.

\begin{tabular}{ccc}
\hline ANO & CR4 & CR8 \\
\hline $\mathbf{2 0 1 2}$ & 0,5146 & 0,7418 \\
$\mathbf{2 0 1 3}$ & 0,5054 & 0,7090 \\
$\mathbf{2 0 1 4}$ & 0,5219 & 0,7069 \\
\hline
\end{tabular}

CR4: Concentração de mercado dos 4 principais exportadores. CR8: Concentração de mercado dos 8 principais exportadores.

O mercado de compensados de madeira também é classificado com concentração moderada (NOCE et al., 2007), pois os quatro principais exportadores do produto representavam menos de $60 \%$ do mercado, no período de 1998 a 2002 , fato esse que é similar ao dos pellets de madeira nos anos de 2012 a 2014. A classificação quando a avaliação é feita para os oito principais exportadores de pellets de madeira foi a mesma, ou seja, concentração moderada. Isso porque em nenhum dos três anos estudados, a representatividade de mercado foi inferior a $80 \%$ das exportações.

\section{CONCLUSÕES}

- A classificação, de acordo com o Índice de Gini, indica que a desigualdade do mercado é de forte a muito forte, com a tendência de que a desigualdade aumente com a concentração das exportações sendo dominada somente pelos Estados Unidos. Isso sugere que, para o Brasil aumentar sua participação no mercado, terá que concorrer diretamente com os produtos norte-americanos, procurando entender quais são os fatores que os tornam tão competitivos.

- A concentração do mercado, ao analisar os quatro ou os oito maiores exportadores, é classificada como moderada, devido ao número elevado de países com exportações significativas no mercado de pellets.

- O aumento das exportações de pellets e os investimentos no setor indicam que o Brasil, nos próximos anos, obterá maior representatividade no mercado internacional de pellets de madeira.

\section{REFERÊNCIAS}

AGHION, P.; BLOOM, N.; BLUNDELL, R.; GRIFFITH, R.; HOWITT, P. Competition and innovation: an inverted-u relationship. The Quarterly Journal of Economics, v.120, p. 701-728, 2005. Disponível em: http://www.jstor.org/stable/25098750. Doi: 10.1093/qje/120.2.701

COELHO JUNIOR, C. M. L.; REZENDE, P. L. J.; OLIVEIRA, D. A. Concentração das exportações mundiais de produtos florestais. Ciência Florestal, v. 23, p. 691-701, 2013. Disponível em: http://dx.doi.org/10.5902/1980509812353. Doi: $10.5902 / 1980509812353$ 
CONSTANTINI, V.; SFORNA, G.; ZOLI, M. INTERPRETING BARGAINING STRATEGIES OF DEVELOPING COUNTRIES IN CLIMATE NEGOTIATIONS. A quantitative approach. Ecological Economics, v. 121, p. 128-139, 2016. Disponível em:

http://dx.doi.org/10.1016/j.ecolecon.2015.11.026.

Doi:10.1016/j.ecolecon.2015.11.026

COSTA, F.; GARCIAS, P. M. Concentração de mercado e desempenho das indústrias brasileiras de papel e celulose - recorrendo à modelagem de fleuriet para analisar o paradigma ecd. Revista de contabilidade e organizações, v. 3, p. 143163, 2009. Disponível em: http://dx.doi.org/10.11606/rco.v3i6.34745. Doi: $10.11606 /$ rco.v3i6.34745

DEUTSCHES INSTITUT FÜR NORMUNG (DIN). En 14588: terminology, definitions and descriptions. Berlim: Cen, 2011. 43 p.

FOOD AND AGRICULTURE ORGANIZATION OF THE UNITED NATIONS. Forestry production and trade, statistics division 2015. Disponível em: http://faostat3.fao.org/download//fo/e. Acesso em 18/10/2015.

GOETZL, A. Developments in the global trade of wood pellets. U.S. International Trade Commission, 28p., 2015.

HEIMANN, J, P.; GONÇALVES, K.; DRESCH, A. R.; SILVA, L. G. C. J. Concentração do mercado de moldura (frame) importadas pelos estados unidos, período de 2005 e 2009. Cerne, v.21, p. 59-65, 2015. Disponível em: http://www.scielo.br/pdf/cerne/v21n1/2317-6342-cerne-21-01-00059.pdf. Doi: 10.1590/01047760201521011435.

HENNESSY, A. D.; LAPAN, H. When different market concentration indices agree. Economics Letters, v.95, p. 234-240, 2007. Disponível em: http://www.sciencedirect.com/science/article/pii/s0165176506003545.

Doi:10.1016/j.econlet.2006.10.011

KARKANIA, V.; FANARA, E.; ZABANIOTOU, A. Review of sustainable biomass pellets production - a study for agricultural residues pellets' market in Greece. Renewable and Sustainable Energy Reviews, v. 16, p. 1426-1436, 2012. Disponível em: http://www.sciencedirect.com/science/article/pii/s1364032111005740. Doi:10.1016/j.rser.2011.11.028

KRISTÖFEL, C.; STRASSER, C.; SCHMID, E.; MORAWETZ, U. B. The wood pellet market in austria: a structural market model analysis. Energy Policy, v. 88, p. 402412, $2015 . \quad$ Disponível em: http://www.sciencedirect.com/science/article/pii/s030142151530166x.

Doi:10.1016/j.enpol.2015.10.039

LAMERS, P.; JUNGINGER, M.; HAMELINCK, C.; FAAIJ, A. Developments in international solid biofuels trade - an analysis of volumes, policies, and market factors. Renewable and Sustainable Energy Reviews, v. 15, p. 2655-2676, 2012. 
Disponível em: http://www.sciencedirect.com/science/article/pii/s1364032112001219. Doi:10.1016/j.rser.2012.02.027

MOBINI, M.; SOWLATI, T.; SOKHANSANJ, S. A simulation model for the design and analysis of wood pellet supply chains. Applied Energy, v. 111, p. 1239-1249, 2013. Disponível em: http://www.sciencedirect.com/science/article/pii/s1364032112001219. Doi:10.1016/j.rser.2012.02.027

NOCE, R.; CARVALHO, A. M. M. R.; CANTO, L. J.; SILVA, L. M.; MENDES, M. L. Medida da desigualdade do mercado internacional de compensado. Cerne, v. 13, p. 107-110, $2007 . \quad$ Disponível em: http://www.ciflorestas.com.br/download.php?tabela=documentos\&id=115\&leitura=s. Doi:10.1590/s0104-77602010000300002 0.36

NOCE, R.; SILVA, L. M.; CARVALHO, A. M. M. R.; SOARES, S. T. Concentração das exportações no mercado internacional de madeira serrada. Revista Árvore, v. 29 , p. 431-437, 2005. Disponível em: http://dx.doi.org/10.1590/s010067622005000300010. Doi:10.1590/s0100-67622005000300010

NOCE, R.; SILVA, L. M.; SOUZA, L. A.; SILVA, M. O.; MENDES, M. L.; CARVALHO, A. M. M. R.; VALVERDE, R. S. Competitividade do brasil no mercado internacional de aglomerado. Revista Árvore, v. 32, p. 113-118, 2008. Disponível em: http://dx.doi.org/10.1590/s0100-67622008000100013. Doi:10.1590/s010067622008000100013

NUNES, L. J. R.; MATIAS, J. C. O.; CATALÃO, J. P. S. Wood pellets as a sustainable energy alternative in portugal. Reneable Energy, v. 85, p. 1011-1016, 2015.

Disponível

em:

http://www.sciencedirect.com/science/article/pii/s0960148115301609.

Doi:10.1016/j.renene.2015.07.065

PESKA-BLANCHARD, M.; DOLZAN, P.; GRASSI, A.; HEINIMÖ, J.; JUNGINGER, M.; RANTA, T.; WALTER, A. Global wood pellets markets and industry: policy drivers, market status and raw material potential. Lea Bioenergy, v. X, p. 1-120, $2007 . \quad$ Disponível em: https://www.researchgate.net/publication/27709106_global_wood_pellets_markets_a nd_industry_policy_drivers_market_status_and_raw_material_potential.

PROSKURINA, S.; HEINIMÖ, J.; MIKKILÄ, M.; VAKKILAINEN, E. The wood pellet business in russia with the role of north-west russian regions: present trends and future challenges. Renewable and Sustainable Energy Reviews, v. 51, p. 730-740, 2015.

Disponível

em:

http://www.sciencedirect.com/science/article/pii/s1364032115006231.

Doi:10.1016/j.rser.2015.06.051

PROTÁsio, T, P.; TRUGILHO, P. F.; SIQUEIRA, H, F.; MELO, I. C. N. A.; ANDRADE, C. R.; JUNIOR, J. B. G. Caracterização energética de pellets in natura e torrificados produzidos com madeira residual de pinus. Pesquisa Florestal Brasileira, v. 35, p. 435-442, 2015. Disponível em: 
http://pfb.cnpf.embrapa.br/pfb/index.php/pfb/article/viewfile/843/456.

Doi: 10.4336/2015.pfb.35.84.843

SELKIMAKI, M.; MOLA-YUDEGO, B.; RÖSER, D.; PRINZ, R.; SIKANEN, L. Present and future trends in pellet markets, raw materials, and supply logistics in sweden and finland. Renewable and Sustainable Energy Reviews, v.14, p. 3068-3075, 2010. Disponível em: http://www.sciencedirect.com/science/article/pii/s1364032110001565. Doi:10.1016/j.rser.2010.06.009

SIKKEMA, R.; STEINER, M.; JUNGINGER, M.; HIEGL, W.; HANSEN, T. M.; FAAIJ, A. The european wood pellet markets: current status and prospects for 2020 . Biofuelss Bioproducts \& Biorefining, v. 5, p. 250-278, 2011. Disponível em: https://www.researchgate.net/publication/227837497_the_european_wood_pellet_m arkets_current_status_and_prospects_for_2020. Doi: 10.1002/bbb.277/full

SPANHOL, A.; NONES, D. L.; KUMABE, F. J. B.; BRAND, M. A. Qualidade dos pellets de biomassa florestal produzidos em santa catarina para a geração de energia. Floresta, v. 45, p. 833-844, 2015. Disponível em: http://ojs.c3sl.ufpr.br/ojs/index.php/floresta/article/view/37950. Doi: 10.5380/rf.v45i4.37950. 833

SPELTER, H.; TOTH, D. North America's Wood Pellet Sector. Research paper fplrp-656. Laboratory ufp, madison, usa (2009).

TRØMBORG, E.; RANTA, T.; SCHWEINLE, J.; SOLBERG, B.; SKJEVRAK, G.; TIFANNY, D. G. Economic sustainability for wood pellets production e a comparative study between finland, germany, norway, sweden and the us. Biomass and Bioenergy, v.57, p. 68-77, 2013. Disponível em: http://www.sciencedirect.com/science/article/pii/s0961953413000457.

Doi:10.1016/j.biombioe.2013.01.030 